\title{
Reactive Power Compensation by Power Capacitor Method
}

\author{
Fazal M*, Waleed Raza M, Khan S and Faizullah \\ Department of electrical engineering, Balochistan University of Information Technology, Pakistan
}

Submission: February 06, 2018; Published: April 13, 2018

*Corresponding author: Fazal Muhammad, Lecturer, Electrical Engineering Department BUITEMS, Pakistan, Tel: + 92-3328068744;

E-mail: fazalkhan00@gmail.com

\begin{abstract}
Reactive power compensation play an important role in modern era because supplier companies take charges of it, if it exceeds a predetermined value so different companies enforce users to compensate it. In this paper, different topologies are discussed but the appropriate method which we are employing is power capacitor topology. This research has design programming based capacitor technique for $200 \mathrm{KVAR}$, $400 \mathrm{~V}$ and detuning factor $7 \%$. We understand standard and requirements regarding capacitor based topologies on the bases of price, qualities and different elements.
\end{abstract}

Keywords: Detuning Capacitor; acceptor circuit; ZEE SILKO company Capacitor; Reactive power

\section{Introduction}

Reactive power compensation play an important role in this modern era because supplier companies take charges of it, if it exceeds a predetermined value so different companies enforce users to compensate it, and to reduce the power consumption. The consumer has to pay electricity charges for his maximum demand in KVA plus the unit consumed if the value of power factor is improved by the customer so there will be annual saving. Power factor improvement results increasing making capacity of plant. The aim is to reduce the reactive power flow so as result reducing the electrical energy charges. Most appropriate method for compensating reactive power flow is power capacitor, which is economical and efficient as well compare to filter and compensating by synchronous condenser, but in this paper, we are designing programmed capacitor bank to compensate the reactive power flow automatically, for that we introduced single, group and bulk power factor correction techniques according to level of customer used (Figure 1).

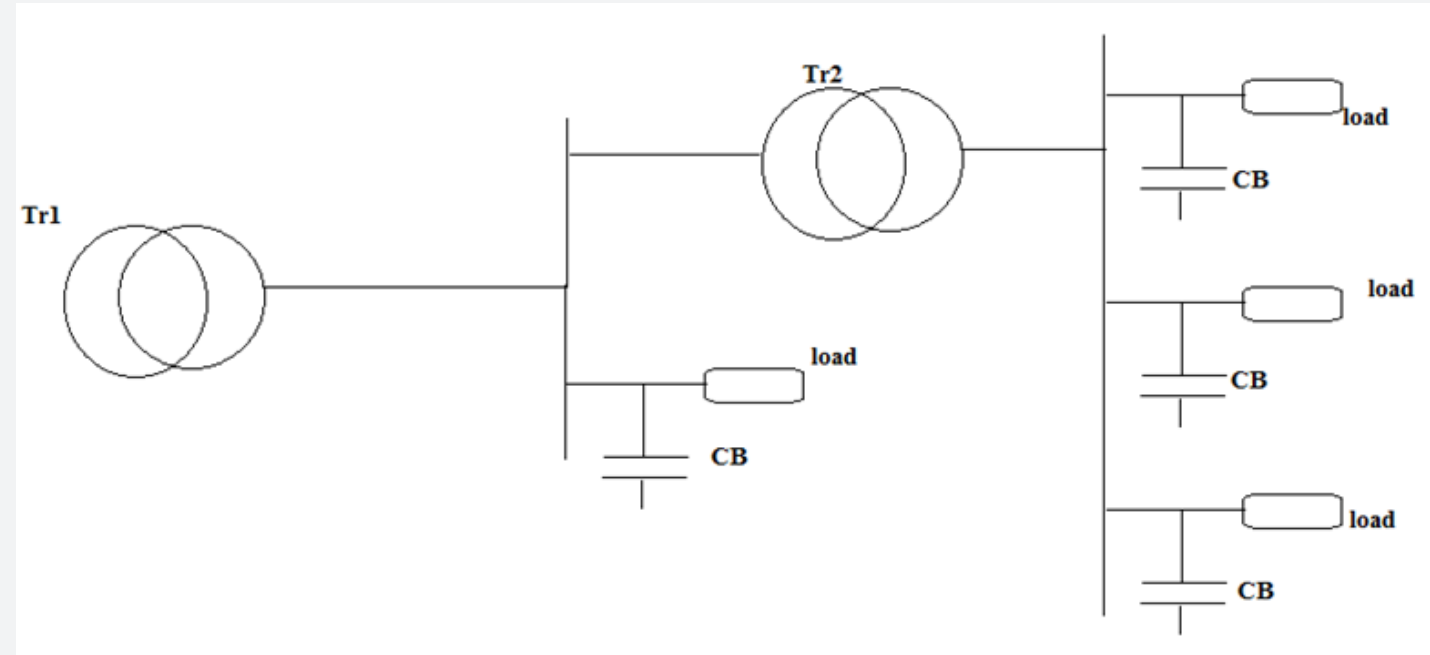

Figure 1: Single PF modification topology. 


\section{Methodology}

\section{Reactive power compensation topologies}

The inductive load causes the low power factor which can be compensate by using capacitive behavior devices which are as follows

1. Capacitor Bank

2. Synchronous electric motors

3. Active filters

4. Hybrid filters

The most appropriate and economical method employing for reactive power compensation is capacitor bank topology.

Capacitor bank is further having 3 major types which are as follows
1. Single PF modification topology

2. Group PF modification topology

3. Bulk PF modification topology

\section{Single PF modification topology}

Here power capacitor is directly connected to device terminal, as result reactive power is compensated at device terminals. Since capacitor can be on or off by the means of working device at load center so there is no need to control it. Here each CB is directly connected to the particular load.

\section{Group PF modification topology}

This method is very helpful because it compensates the number of loads connected to same switchgear. Here bank of capacitor is controlled by programmable device and also protection is applying for number of capacitor (Figure 2).

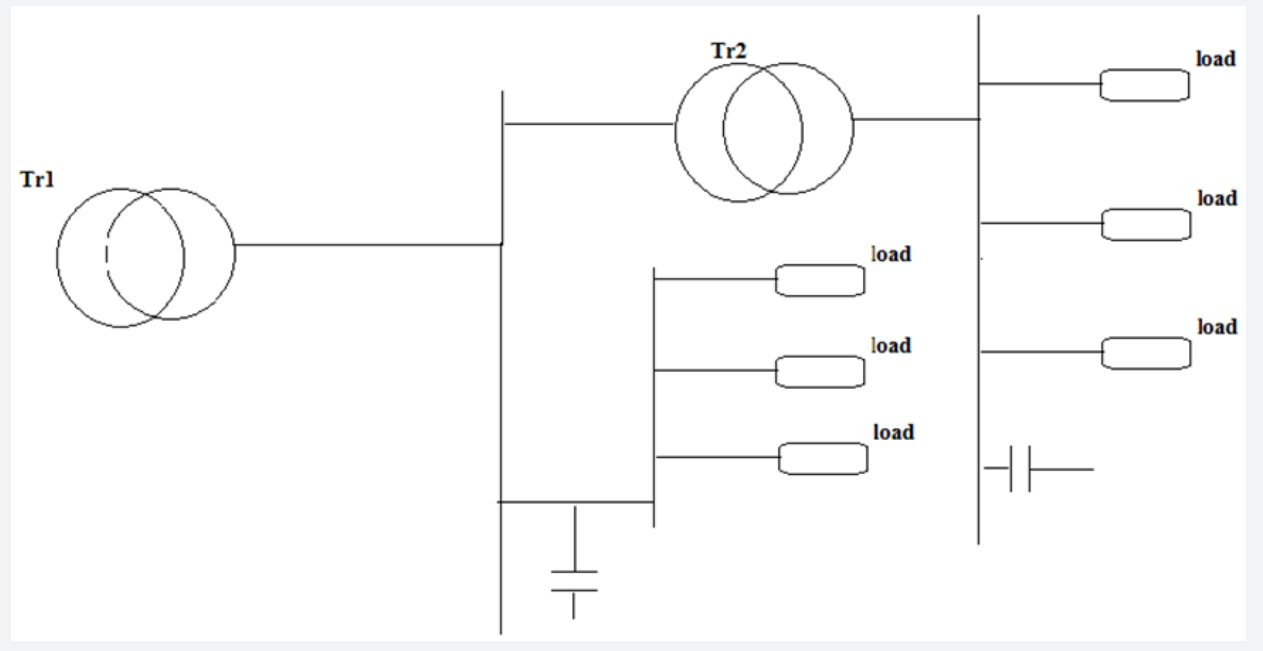

Figure 2: Group PF modification topology.

\section{Bulk PF modification topology}

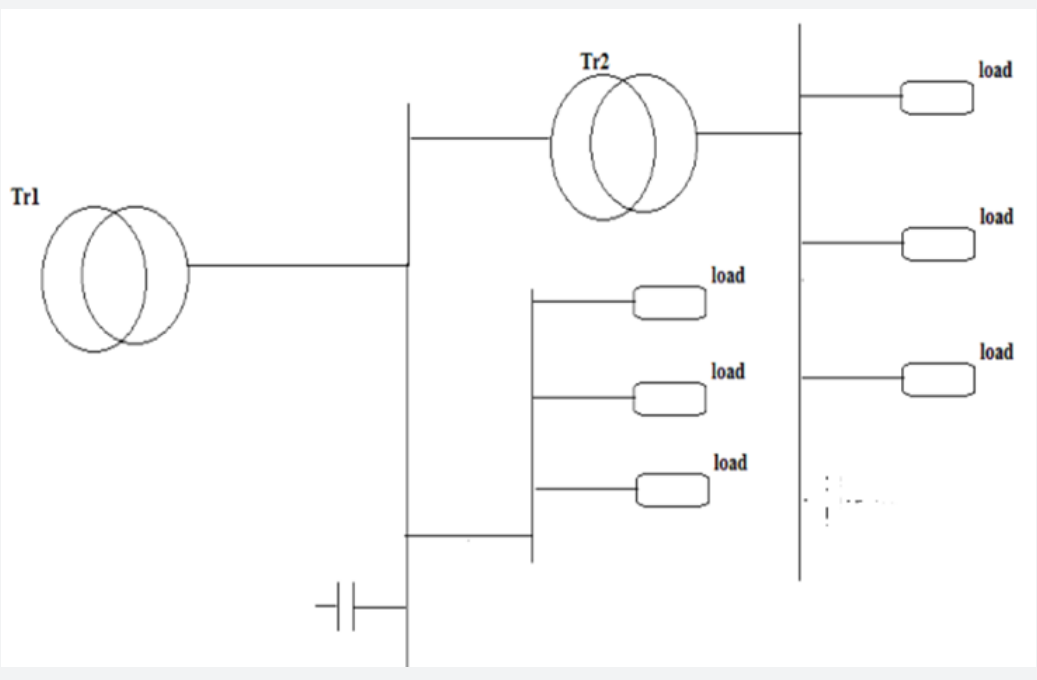

Figure 3: Bulk PF modification topology. 
This method is very important for reactive power compensation for whole switchyard. Whole PS is loaded by reactive current as result capacitor having large power Regulation so group PF modification is very helpful in such case rather than bulk (Figure 3).

\section{Results and Discussion}

\section{Power capacitor and detuning reactor}

For required voltage and power the reactor and capacitor should be connected in series. After analysis different data, we have to employ power capacitor with rated voltage as according to the formula.

$$
\begin{aligned}
& P R=P N(V S / V N) \ldots \ldots \ldots \ldots \ldots \\
& P R=20 x(0.4 / 0.44) 2=16.52 \mathrm{kvar} \ldots . .
\end{aligned}
$$

The calculation can have withheld if there is no reactive power in series with respective capacitor.

\section{Acceptor circuit}

Capacitor and cascaded reactor shows acceptor network so respective capacitor bank should remove distorted voltage and current connected with CB. Acceptor circuit basically filtrate the higher order harmonics which is the capability of that circuit termed as detuning factor which is defined by formula

$$
\text { Detuning Factor P\% = (FN/FR) } x 100 \ldots
$$

Typical range of higher order harmonics limited includes $5^{\text {th }}$ and $7^{\text {th }}$ harmonics. Which are usually present in the main and biggest share is involve in supplying current. The data taken for the calculation below is Capacitor

$$
\begin{aligned}
& Q c n=20 \mathrm{kvar} \\
& F n=50 \mathrm{cycle} / \text { per second } \\
& \text { Ucn }=440 \mathrm{~V} \\
& \text { Others } \\
& \text { Un }=400 \mathrm{~V} \\
& P=7 \text { Percent }
\end{aligned}
$$

The ratio $\mathrm{M}$ indicates to find total capacitor with required power when reactor is cascaded in it.

$$
\begin{aligned}
& M=Q C N / Q R E S=20 / 18=1.1 \ldots \ldots(4) \\
& Q C B R=Q c b \times M=200 x 1.1=220 \mathrm{kvar}
\end{aligned}
$$

For number of capacitors the required power should be distributed. For required capacitor rating ZES SILKO Company was chosen because it is pronounced company among different supplier.

\section{CSADG 1-0,44/20,1 capacitor}

Gas filled capacitor 20Kvar: Gas filled Capacitor CSADG 1-0.44/20 from ZES Silko With N2 Dielectric used for power factor correction are used in power three phase networks $440 \mathrm{~V}$, $50 \mathrm{~Hz}$ and capacity $20 \mathrm{kvar}$, the figure is shown below Figure 4 .

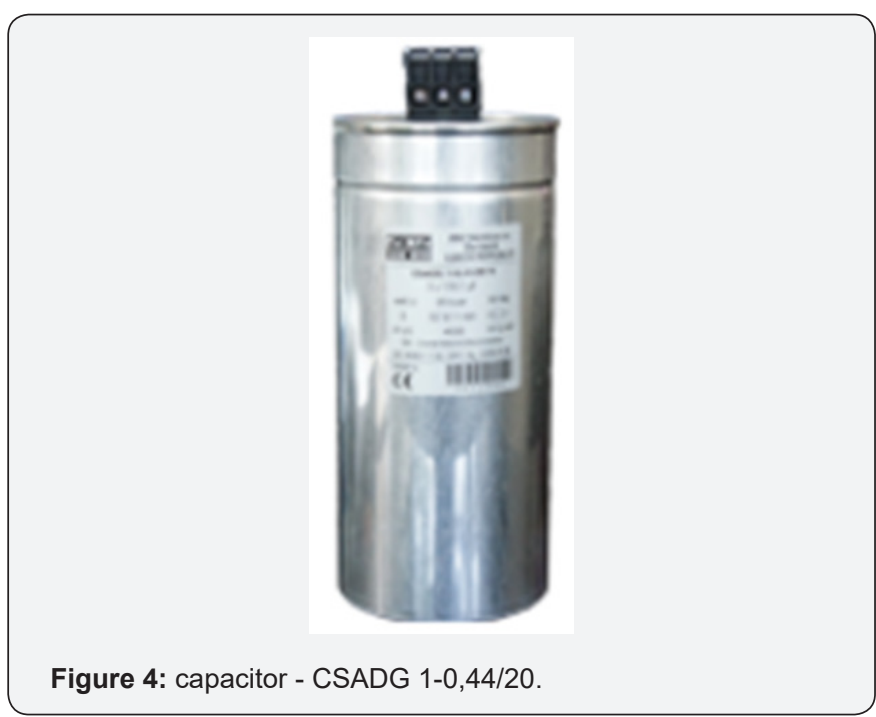

Other we use are

\section{CSADP 3-0, 44/40, 5 capacitors}

Main Circuit Diagram: For connection diagram of capacitor bank, we draw both control and main circuit diagram. The respective switchyard is connected to capacitor bank. There is three stage network incomings to supply the capacitor bank from the feeder, the incoming power is distributed through the bus bars then onward. The cross section of the bus so current can be withheld very carefully. Flowing through the device. for capacitor bank, there are three insulators which gives short circuit strength of about 20-30kA.The connection L1,L2 and L3 represents the point of connection of the capacitors and respective reactors with the bus bars (Figure 5).

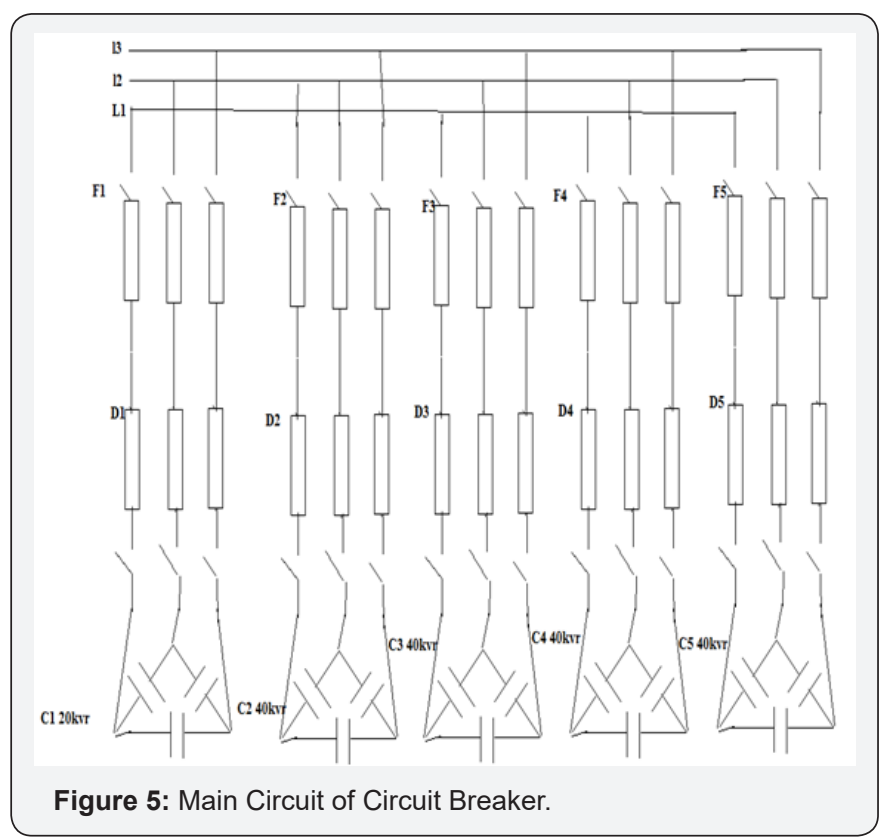

The three cooper bus bars L1, L2 and L3 are connected through the wires to the switch disconnectors F-F6. All switch 
disconnectors has the same current strength of 160A. The terminals 2,4,5 of each disconnector are connected to the three phase reactor (D1-D5). Each reactor has thermal protection (contact 11 and 14). Next, the reactors are connected in series through the contactors (K1-K5). The terminals A1 and A2 (coil of the contactor supplied by $230 \mathrm{~V}$ AC source) trip the contacts of the contactor.

Control Circuit: Control equipment is very important for the protection needs to terminal stripe. It will cross all network to make the circuit work.

\section{Conclusion}

Power capacitors techniques are most common for reactive power compensation. Many companies provide capacitor bank components which needs to be compared [1-6]. I compared all the capacitor bank components offered by manufacturers. It was very time consuming task, since I had to pay attention to each detail regarding functions and features of power factor regulators, the parameters of power capacitors, reliability of contactors and reactors. The more complicated task is determining the rating of capacitor with detuning factor 7 percent then the main and control circuit diagram is determined.

\section{References}

1. Alexandra VM (2006) Electric Power Systems: A Conceptual Introduction (Wiley Survival Guides in Engineering and Science)sl : Wiley-IEEE Press.

2. Praca Z (1996) Poradnik inżyniera elektryka. Tom 2. Warszawa : Wydawnictwo Naukowo Techniczne.

3. Czarnecki L (1983) Reactive power under non sinusoidal conditions: IEEE Tran. on Power Apparatus and Systems.

4. Kopka J (2010) Power Factor Correction-Design of automatic capacitor bank. Wroclaw: Wroclaw University of Technology.

5. EPCOS. MKV Power Electronic Capacitors.

6. Walidziak, Tomasz. Kondensatory energetyczne niskich i rednich napi Olsztyn: Elma Enegria.

\section{Your next submission with Juniper Publishers will reach you the below assets}

- Quality Editorial service

- Swift Peer Review

- Reprints availability

- E-prints Service

- Manuscript Podcast for convenient understanding

- Global attainment for your research

- Manuscript accessibility in different formats

( Pdf, E-pub, Full Text, Audio)

- Unceasing customer service

Track the below URL for one-step submission https://juniperpublishers.com/online-submission.php 